Opinion

\title{
On climate change
}

\section{Opinion}

Climate degradation is a single problem for the whole planet and it is useless to look for any local causes of natural disasters, heavy rainfall or drought. The Paris Agreements of 2015 call for a reduction in the emission of carbon dioxide. This is not a proven assumption. There are no convincing arguments for the direct dependence of the increase in the level of the oceans on the increase of $\mathrm{CO}_{2}$ in the atmosphere. "Climate Change Mitigation and Adaptation," the need for which, 750 experts say, leads to humility with climate change. This leads to a distraction of humanity from finding out the true causes of climate change, the loss of time, to a catastrophe. Attempts to reduce fuel combustion are certainly necessary, but they are microscopic in performance.

As a result of human activity, the functions of the main part of the water have changed. Water at every moment of its movement must fulfill its labor mission - to go the way programmed by nature - to supply biota, mineral and organic substances, and clean it, to escape into the atmosphere with the moisture of breathing, transpiration and other excretions of living organisms. Man destroys this link. Water comes with precipitation and returns to the atmosphere by artificial evaporation from arable land, asphalt, reservoirs, dumps. In total, people took from nature $63 \%$ of the inhabited land (data of 2015) for these purposes, each hectare of which contained 20tons of underground living creatures. These are microbes, worms, and so on living creatures that, in symbiosis with plants and terrestrial populations, absorb moisture, transform in food chains and exhale purely individual pairs, which we call natural or organic vapors. Human intervention in the circulation of water reduces food chains, and water from asphalt and other destroyed areas evaporates immediately after precipitation. We call this evaporation artificial. Even more artificial fumes are produced by industry and utilities around the world. The total artificial evaporation creates unprecedented volumes of water in the atmosphere, which destroyed the mechanism of atmospheric phenomena, perfected for millions of years. The cyclicity, massiveness and places of precipitation have changed. The melting of glaciers, perhaps, has not changed - this is also an assumption. The new regime of water circulation does not ensure the former accumulation of snow in the Arctic regions. Reduced water path in the clouds and premature precipitation and leads to an increase in the level of the oceans.

Only the all-round and worldwide return to nature of organic

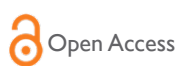

CrossMark

Volume 7 Issue 5 - 2018

\author{
Oleg Halidullin \\ Kazakh National University, Alb-Farabi, Russia
}

Correspondence: Oleg Halidullin, Kazakh National University, Junior researcher Alb-Farabi, Russia, Email 7II8215@mail.ru

Received: July 30, 2018 | Published: October 31, 2018

fumes and artificial reduction can stop raising the level of the ocean and solve your problems.

Among the measures to reduce artificial fumes should be the total total water saving in everyday life by every person, every enterprise of all branches of agriculture and industry. Reconstruction of all agriculture with the introduction of shallow plowing, drip irrigation, other ways to reduce water consumption. And all this should be done on every scrap of the remaining land around the world and not only on agriculture - in all branches of human life.

One of the most capacious in artificial evaporation is man-made reservoirs. Now the construction of new hydroelectric power stations with the flooding of large areas is increasing everywhere. Full stop of projects and construction of new reservoirs, gradual liquidation of existing for restoration of a historical biota is necessary. There are interesting technical solutions for the conservation of power generation without dams and the accumulation of water above the surface of rivers.

Urgently begin landscaping of roofs and walls of all structures in the world, and the construction of new industries, urban infrastructure and even housing to be moved underground and under water. There are such projects.

\section{Acknowledgements}

None.

\section{Conflict of interest}

Author does not have any conflicts of interests. 